\title{
Climate explains population divergence in drought-induced plasticity of functional traits and gene expression in a South African Protea
}

\author{
Melis Akman ${ }^{1}$, Jane Carlson ${ }^{2}$, and Andrew Latimer ${ }^{3}$ \\ ${ }^{1} \mathrm{UC}$ Berkeley \\ ${ }^{2}$ Affiliation not available \\ ${ }^{3} \mathrm{UC}$ Davis
}

June 11, 2020

\begin{abstract}
Long term environmental variation often drives local adaptation and leads to trait differentiation across populations. Additionally, when traits change in an environment-dependent way through phenotypic plasticity, the underlying genetic variation will also be under selection, but only in the inducing environment. Both of these processes will create a landscape of differentiation across populations in trait means as well as their plasticity. However, studies uncovering environmental drivers of this variation are scarce. With this work, we studied drought responses in seedlings of a shrub species from the Cape Floristic Region, the common sugarbush (Protea repens). We measured morphological and physiological traits as well as whole transcriptomes in 8 populations that represent both the climatic and the geographic distribution of this species. We found that there is substantial variation in how populations respond to drought, but we also observe common patterns such as reduced leaf size and thickness and upregulation of stress- and down-regulation of growth-related gene groups. Both environmental heterogeneity and milder source site climates were associated with higher plasticity in various traits and co-expression gene networks. By uncovering associations between traits, trait plasticity, co-expression gene networks with source site climate, we showed that temperature plays a bigger role in shaping these patterns when compared to precipitation, in line with recent changes in the region due to climate change. We also found that traits respond to climatic variation in a context dependent manner: some associations between traits and climate were apparent only under certain growing conditions.
\end{abstract}

\section{Hosted file}

repens_drydown_manuscript_revision.pdf available at https://authorea.com/users/332198/ articles/458634-climate-explains-population-divergence-in-drought-induced-plasticityof-functional-traits-and-gene-expression-in-a-south-african-protea 

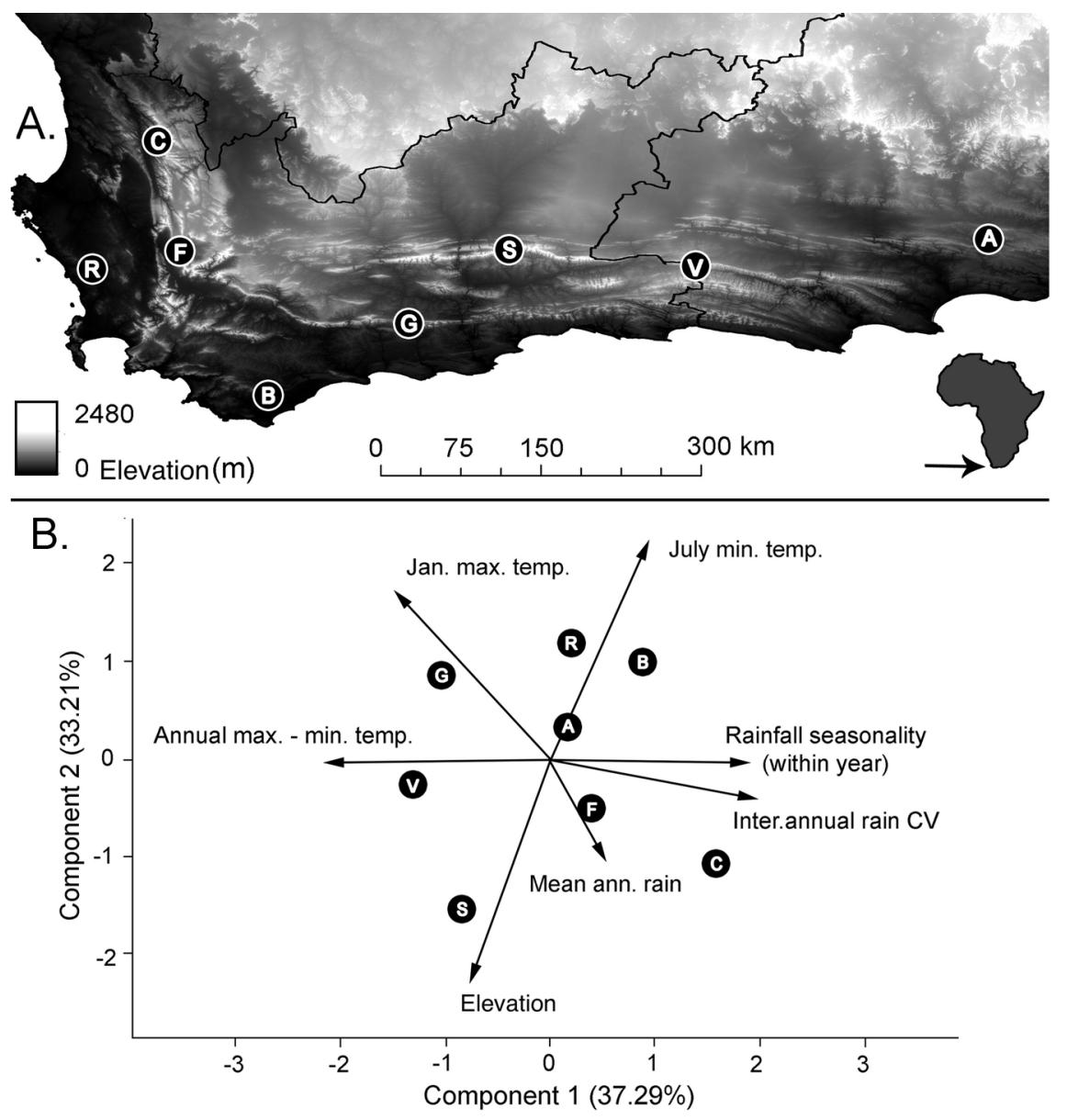

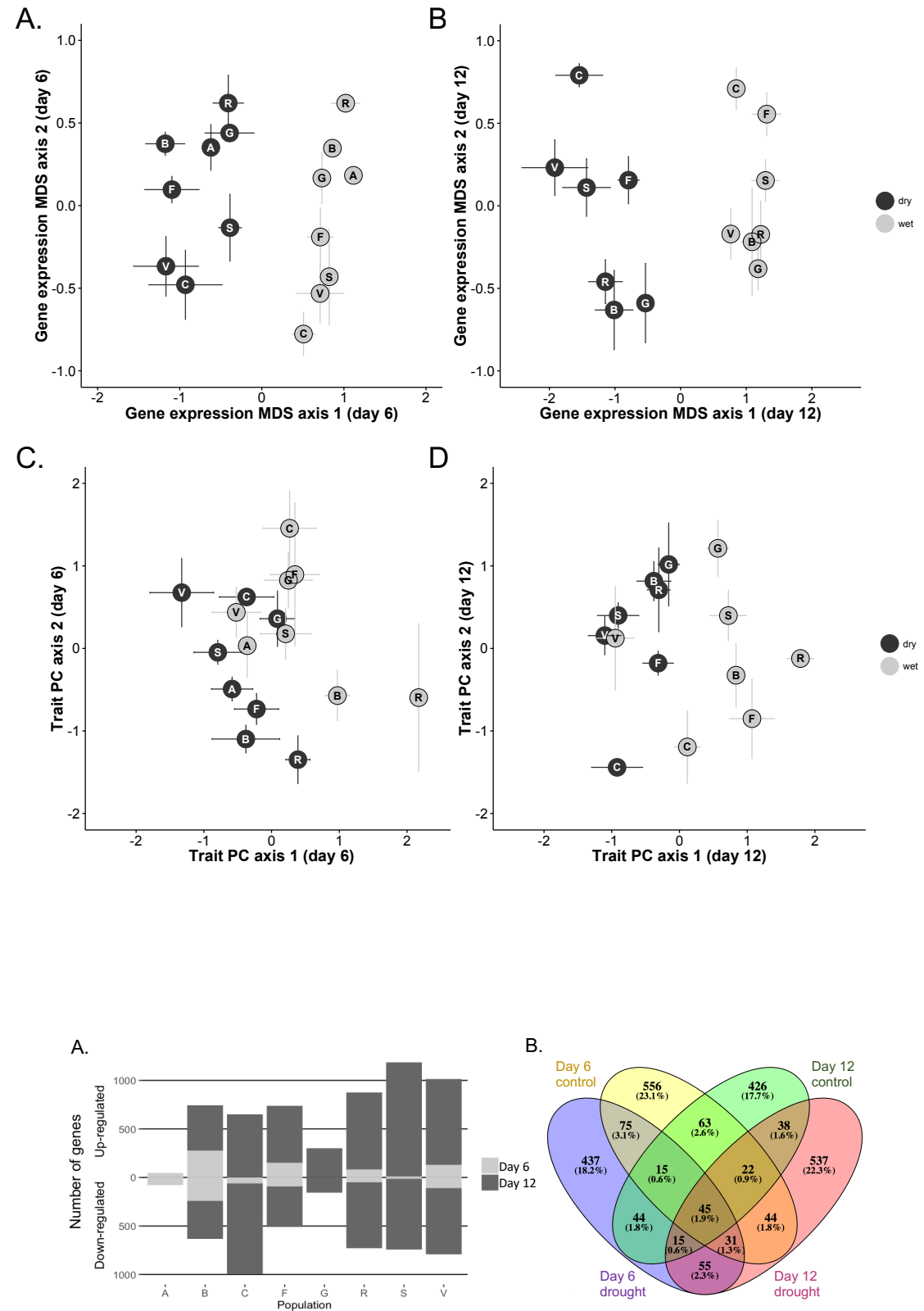


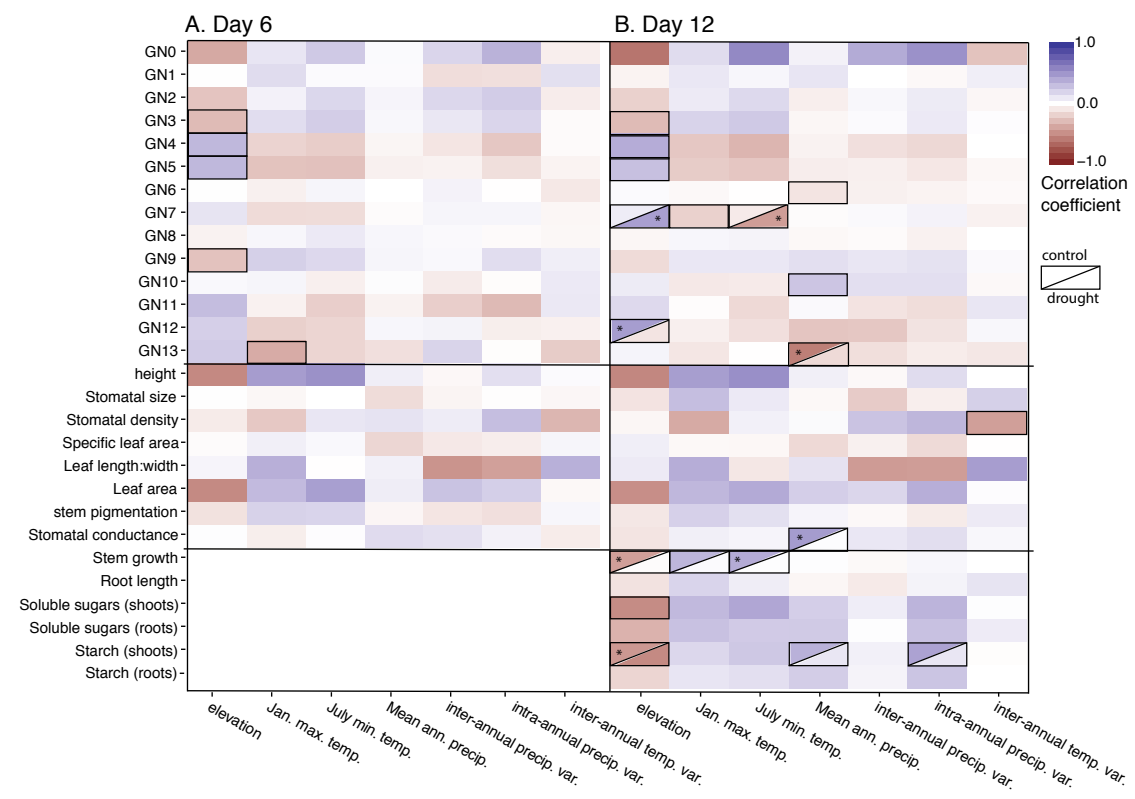



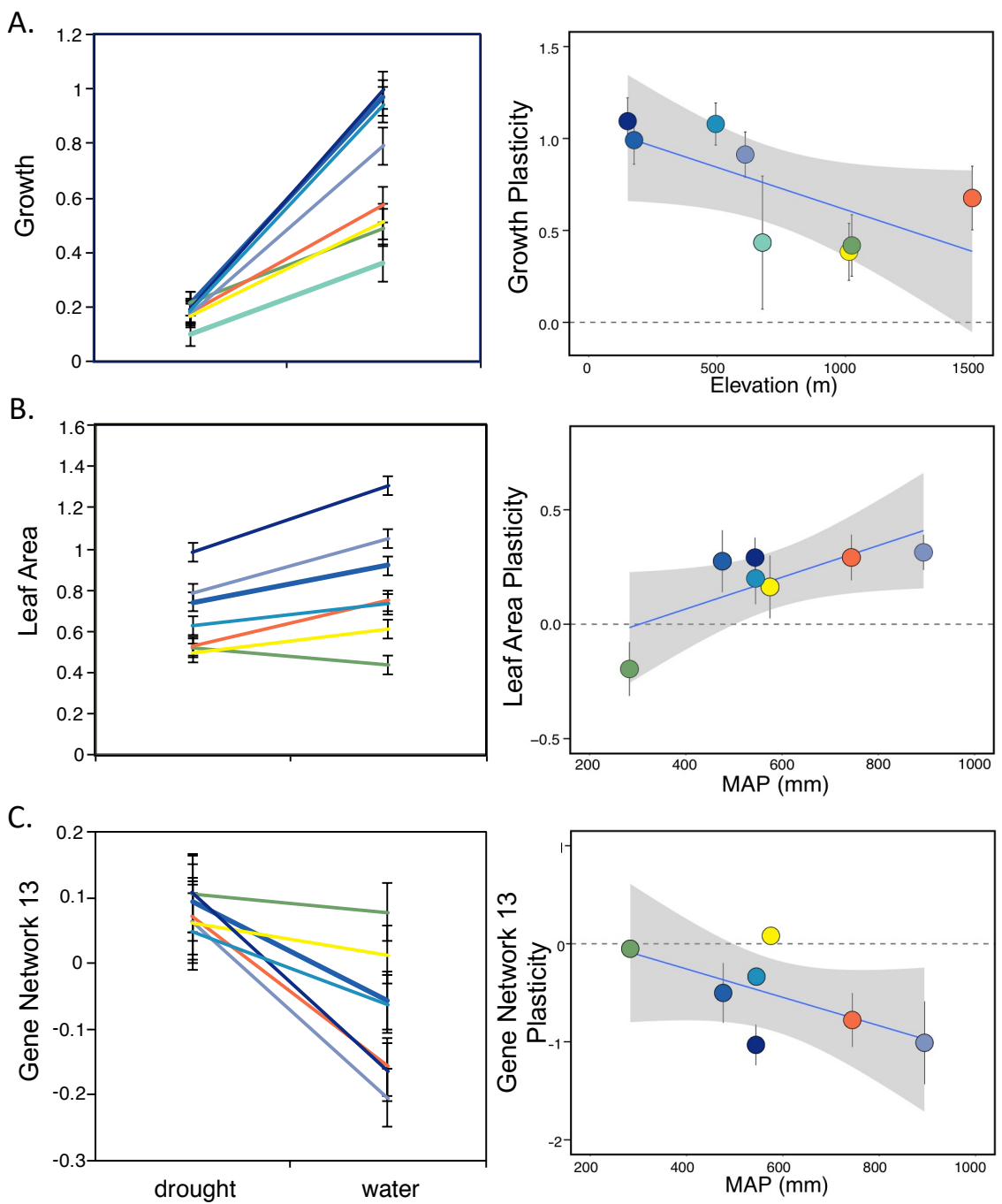

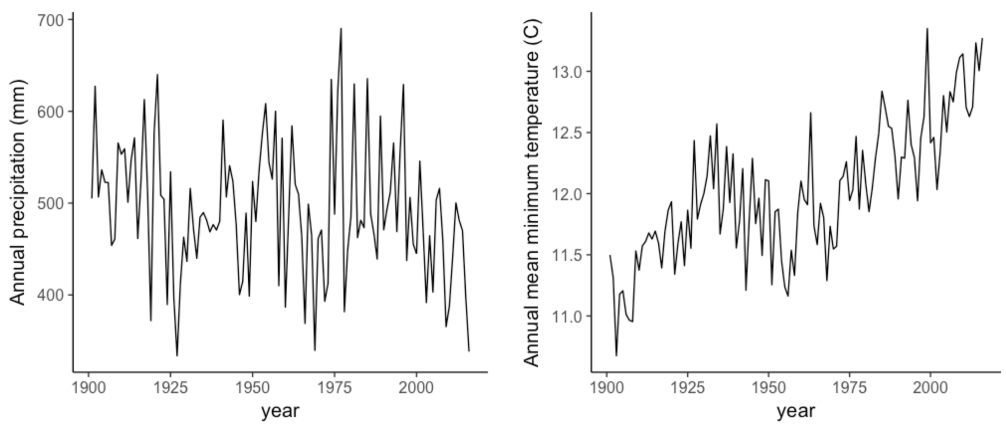
Table 1. Results of linear mixed models testing functional trait and performance differences of Protea repens seedlings at 6 and 12 days into the dry down experiment. The model compares values between watered and unwatered treatments as well as among 8 wild-sourced populations and the population by treatment interaction. Significant values are bolded.

\begin{tabular}{|c|c|c|c|c|c|c|c|c|c|}
\hline \multirow{2}{*}{$\begin{array}{l}\text { Response } \\
\text { variable }\end{array}$} & \multirow[b]{2}{*}{ Fixed effects } & \multicolumn{4}{|c|}{ day 6} & \multicolumn{4}{|c|}{ day 12} \\
\hline & & df & Chi-sq & P-value & q-val & $\mathrm{df}$ & Chi-sq & $p$-value & q-value \\
\hline \multirow{3}{*}{$\begin{array}{l}\text { Leaf } \\
\text { area }\left(\mathrm{cm}^{2}\right)\end{array}$} & Population & 7 & 49.91 & $<0.0001$ & $<0.0001$ & 6 & 69.16 & $<0.0001$ & $<0.0001$ \\
\hline & Treatment & 1 & 0.17 & 0.678 & 0.881 & 1 & 23.39 & $<0.0001$ & $<0.0001$ \\
\hline & Pop. $\times$ Trt. & 7 & 8.61 & 0.282 & 0.423 & 6 & 13.3 & 0.039 & 0.050 \\
\hline \multirow{3}{*}{$\begin{array}{l}\text { SLA } \\
\left(\mathrm{cm}^{2} / \mathrm{g}\right) \\
\text { Log transform }\end{array}$} & Population & 7 & 5.15 & 0.642 & 0.881 & 6 & 15.35 & 0.018 & 0.027 \\
\hline & Treatment & 1 & 12.13 & 0.0005 & 0.002 & 1 & 73.14 & $<0.0001$ & $<0.0001$ \\
\hline & Pop. $\times$ Trt. & 7 & 19.23 & 0.008 & 0.027 & 6 & 16.71 & 0.010 & 0.017 \\
\hline \multirow[t]{3}{*}{ LWR } & Population & 7 & 67.48 & $<0.0001$ & $<0.0001$ & 6 & 78.55 & $<0.0001$ & $<0.0001$ \\
\hline & Treatment & 1 & 0.06 & 0.814 & 0.881 & 1 & 1.86 & 0.173 & 0.210 \\
\hline & Pop. $\times$ Trt. & 7 & 3.47 & 0.839 & 0.881 & 6 & 1.52 & 0.958 & 0.958 \\
\hline \multirow{3}{*}{$\begin{array}{l}\text { Stomatal } \\
\text { density }\end{array}$} & Population & 7 & 17.46 & 0.015 & 0.040 & 6 & 29.73 & $<0.0001$ & 0.0001 \\
\hline & Treatment & 1 & 3.07 & 0.080 & 0.192 & 1 & 12.95 & 0.0003 & 0.0007 \\
\hline & Pop. $\times$ Trt. & 7 & 9.56 & 0.215 & 0.369 & 6 & 3.59 & 0.732 & 0.765 \\
\hline \multirow{3}{*}{$\begin{array}{l}\text { Stomatal } \\
\text { pore size (um) }\end{array}$} & Population & 7 & 3.87 & 0.795 & 0.881 & 6 & 21.92 & 0.001 & 0.002 \\
\hline & Treatment & 1 & 0.04 & 0.844 & 0.881 & 1 & 27.68 & $<0.0001$ & $<0.0001$ \\
\hline & Pop. $\times$ Trt. & 7 & 3.05 & 0.881 & 0.881 & 6 & 14.27 & 0.027 & 0.038 \\
\hline \multirow{3}{*}{$\begin{array}{l}\text { Stem } \\
\text { pigmentation }\end{array}$} & Population & 7 & 34.13 & $<0.0001$ & $<0.0001$ & 7 & 38.51 & $<0.0001$ & $<0.0001$ \\
\hline & Treatment & 1 & 1.85 & 0.174 & 0.336 & 1 & 0.42 & 0.515 & 0.579 \\
\hline & Pop. $\times$ Trt. & 7 & 10.12 & 0.182 & 0.336 & 7 & 5.71 & 0.574 & 0.630 \\
\hline \multirow{3}{*}{$\begin{array}{l}\text { Stem } \\
\text { height }(\mathrm{cm})\end{array}$} & Population & 7 & 105.34 & $<0.0001$ & $<0.0001$ & 7 & 121.24 & $<0.0001$ & $<0.0001$ \\
\hline & Treatment & 1 & 5.9 & 0.015 & 0.040 & 1 & 49.4 & $<0.0001$ & $<0.0001$ \\
\hline & Pop. $\times$ Trt. & 7 & 4.1 & 0.768 & 0.881 & 7 & 6.86 & 0.443 & 0.511 \\
\hline \multirow{3}{*}{$\begin{array}{l}\text { Stomatal } \\
\text { conductance }\end{array}$} & Population & 7 & 0 & 0.254 & 0.406 & 6 & 17.52 & 0.008 & 0.014 \\
\hline & Treatment & 1 & 0 & $<0.0001$ & $<0.0001$ & 1 & 104.7 & $<0.0001$ & $<0.0001$ \\
\hline & Pop. $\times$ Trt. & 7 & 0 & 0.148 & 0.323 & 6 & 23.43 & 0.0007 & 0.001 \\
\hline
\end{tabular}

